WILEY-VCH

"This is the peer reviewed version of the following article: Angew. Chem. Int. Ed. 2018, 57 (35), 11203-11207, which has been published in final form at DOI: 10.1002/anie.201803967. This article may be used for non-commercial purposes in accordance with Wiley Terms and Conditions for Self-Archiving published at http://olabout.wiley.com/WileyCDA/Section/id-820227.html." 


\title{
Organocatalyzed Domino [3+2] Cycloaddition/Payne-Type Rearrangement using Carbon Dioxide and Epoxy Alcohols
}

\author{
Sergio Sopeña, ${ }^{[a]}$ Mariachiarra Cozzolino, ${ }^{[a]}$ Cristina Maquilón, ${ }^{[a]}$ Eduardo C. Escudero-Adán, ${ }^{[a]}$ Marta \\ Martínez Belmonte, ${ }^{[a]}$ and Arjan W. Kleij ${ }^{*[a][b]}$
}

\begin{abstract}
An unprecedented organocatalytic approach towards highly substituted cyclic carbonates from tri- and tetra-substituted oxiranes and carbon dioxide has been developed. The protocol involves the use of a simple and cheap superbase under mild, additive- and metal-free conditions towards the initial formation of a less substituted carbonate product that equilibrates to a tri- or even tetra-substituted cyclic carbonate under thermodynamic control. The latter are conveniently trapped in situ providing overall a new domino process for synthetically elusive heterocyclic scaffolds. Control experiments provide a rationale for the observed cascade reactions, which demonstrate high similarity with the well-known Payne rearrangement of epoxy alcohols.
\end{abstract}

The chemistry of cyclic organic carbonates has been developed to a high level of sophistication over the years. ${ }^{[1]}$ In particular, these heterocyclic structures were initially targeted for application as electrolytes of lithium ion batteries and useful precursors towards polycarbonate polymers. ${ }^{[2]}$ More recently, focus has shifted to the use of cyclic carbonates as synthetic precursors for a range of fine-chemical and pharma-relevant scaffolds. ${ }^{[3]}$ In this respect, both the functionalization and the degree of substitution of the cyclic carbonate ring has proven to be crucial to develop catalytic procedures that allow for enantio- or diastereoselective transformations including the formation of allylic compounds, ${ }^{[4]}$ heterocyclic scaffolds ${ }^{[5]}$ and macrocyclic compounds ${ }^{[6]}$ among others. ${ }^{[7]}$ Therefore, synthetic methodologies that give easy access to highly substituted and functionalized cyclic carbonates have gained much importance over the last years and are crucial towards further advancing these synthetic blocks.

The most popular and straightforward approach towards cyclic carbonate synthesis is the [3+2] cycloaddition of $\mathrm{CO}_{2}$ to epoxides under Lewis acid catalysis. ${ }^{[8]}$ Despite the considerable progress noted over the years in this field, the use of tri- and even tetrasubstituted epoxides as coupling partners has been extremely challenging due to the steric requirements of these reactions. ${ }^{[9]}$ The relevance of highly substituted carbonates is illustrated by the occurrence of several natural compounds such as the triterpenoid carbonate Chukvelutin $\mathrm{D}$ and the sesquiterpenoid carbonate Hololeucin (Scheme 1a). ${ }^{[10]}$ While

[a] S. Sopeña, M. Cozzolino, Dr. E. C. Escudero-Adán, Dr. Marta Martínez Belmonte, Prof. Dr. A. W. Kleij, Institute of Chemical Research of Catalonia (ICIQ), the Barcelona Institute of Science and Technology, Av. Països Catalans 16, 43007 - Tarragona, Spain E-mail: akleij@iciq.es

[b] Prof. Dr. A. W. Kleij

Catalan Institute of Research and Advanced Studies (ICREA), Pg Lluís Companys 23, 08010 Barcelona, Spain

Supporting information for this article is given via a link at the end of the document biosynthetic pathways exist towards these complex structures, no synthetic methodologies towards tetra-substituted cyclic carbonates from epoxides and $\mathrm{CO}_{2}$ have been reported to date. Therefore, the discovery of new concepts that can alleviate the problems associated with the formation of these highly substituted cyclic carbonates can revive new potential of these heterocycles in synthetic organic chemistry.

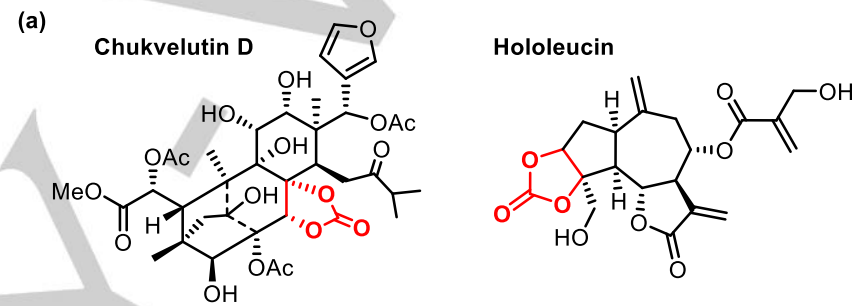

(b)

$$
\text { Payne Rearrangement }
$$<smiles>[R]C(O)C1CO1</smiles>

(c)

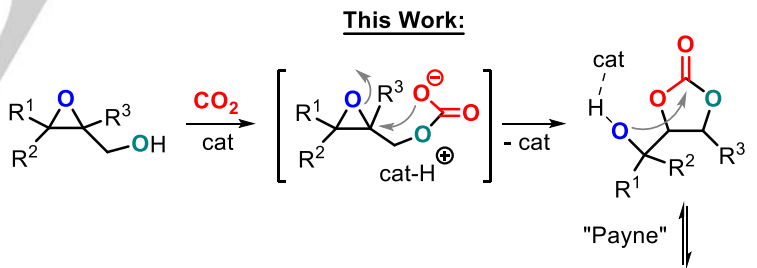

- Metal- \& additive-free

- Domino process

- Elusive carbonates

- Mild conditions
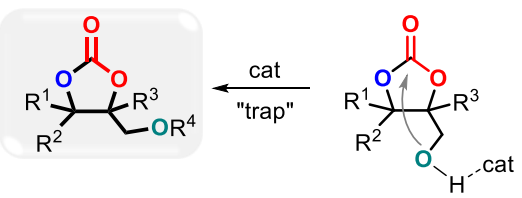

Scheme 1. (a) Naturally occurring cyclic carbonates Chukvelutin D and Hololeucin with their cyclic carbonate fragments in red. (b) Base-assisted Payne rearrangement of epoxy alcohols. (c) New organocatalytic approach towards elusive tri- and tetra-substituted cyclic carbonates. Cat stands for catalyst.

In the course of our research program towards the creation of more complex cyclic carbonate structures, ${ }^{[7 d, 9 a+d, 11]}$ we reasoned that the base-assisted isomerization of 2,3-epoxy alcohols known as the Payne rearrangement (Scheme 1b) ${ }^{[12]}$ offers a paradigmatic scenario towards the synthesis of highly substituted cyclic carbonates. We recently reported a substrate-controlled divergent synthesis of cyclic carbonates and carbamates from epoxy alcohols and amines, respectively, under $\mathrm{Al}(\mathrm{III})$ catalysis. ${ }^{[13]}$ This work showed the potential of the Al-catalyst to 
act as a bifunctional entity with built-in proton-relay capabilities, and further demonstrated a crucial role for the alcohol unit of the substrate. We envisioned that a proper organocatalyst could combine both (1) proton-shuttling potential thereby mediating the synthesis of the cyclic carbonate from an epoxy alcohol and $\mathrm{CO}_{2}$, and (2) induce subsequently a base-assisted Payne-type rearrangement of the hydroxymethyl-substituted cyclic carbonate. By selectively trapping of the more reactive hydroxy-methyl substituted carbonate (Scheme 1c), a simple and conceptually novel route towards structurally elusive tri- and tetrasubstituted cyclic carbonates would become available. Herein we present a new metal- and nucleophile-free one-pot domino strategy generally applicable towards [3+2] cycloadditions involving highly substituted epoxy alcohols and $\mathrm{CO}_{2}$ as substrates. As far as we are aware, this catalytic process is unprecedented in product

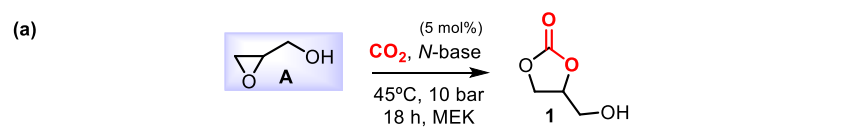

(b)

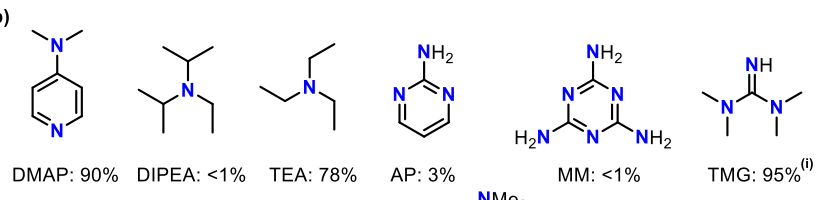

DMAP: $90 \%$ DIPEA: $<1 \%$ TEA: $78 \% \quad$ AP: $3 \%$ OTG: $60 \%$ SQA: $26 \%$

(c)

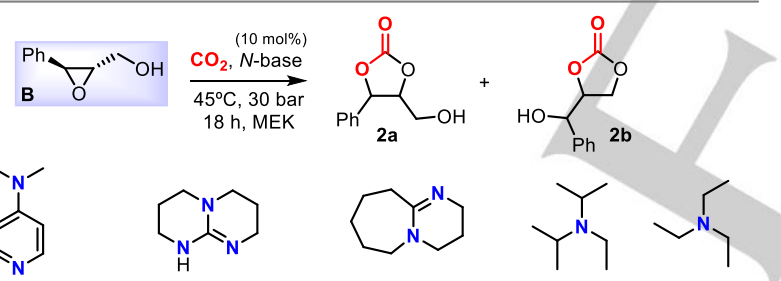

\begin{tabular}{|c|c|c|}
\hline $\begin{array}{l}\text { DMAP: } 45 \% \\
\mathbf{2 a}: \mathbf{2} \mathbf{b}=1: 13\end{array}$ & $\begin{array}{c}\text { TBD: } 80 \% \\
\mathbf{2 a}: 2 \mathbf{b}=1: 9\end{array}$ & $\begin{array}{c}\text { DBU: } 87 \% \\
\mathbf{2 a}: 2 \mathbf{b}=1: 2.5\end{array}$ \\
\hline
\end{tabular}

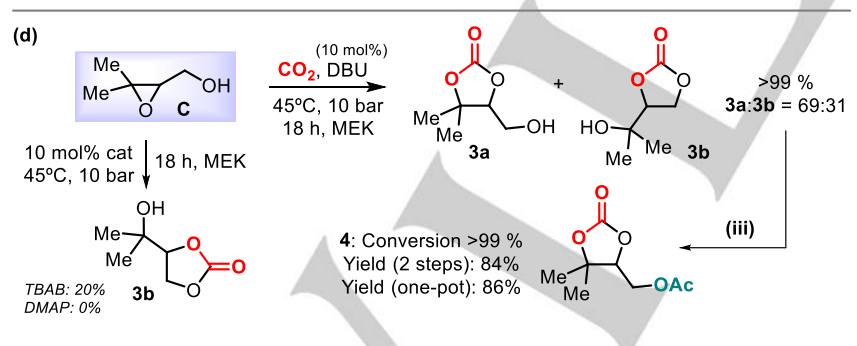

Scheme 2. [a] Screening of various $N$-containing bases to convert glycidol $\mathbf{A}$ and $\mathrm{CO}_{2}$ into its respective cyclic carbonate. Conditions used: glycidol (8.0 $\mathrm{mmol}), N$-base $(5.0 \mathrm{~mol} \%)$, mesitylene (10 mol\%), MEK $(5.0 \mathrm{~mL}), 45^{\circ} \mathrm{C}, 10 \mathrm{bar}$, $18 \mathrm{~h}$. [b] All reported yields for $\mathbf{1}, \mathbf{2} \mathbf{a} / \mathbf{2} \mathbf{b}$ and $\mathbf{3 a} / \mathbf{3 b}$ are based on NMR measurements using mesitylene as internal standard, unless noted otherwise. Details: (i) Polyether (3\%) was also formed. (ii) Isolated yield after chromatographic purification. [c] Comparison between DMAP, TBD and DBU in the synthesis of carbonates $\mathbf{2} \mathbf{a}$ and $\mathbf{2} \mathbf{b}$ from $(R, R)$-phenyl glycidol. The combined NMR yield for $\mathbf{2} \mathbf{a}+\mathbf{2} \mathbf{b}$ is reported. [d] DBU-catalyzed conversion of trisubstituted epoxide C. Details: (iii) DBU (1 equiv), acetyl imidazole (Aclm; 1.5 equiv), rt, $1.5 \mathrm{~h}$; isolated yields are reported. scope as there are no previous reports on formation of tetrasubstituted cyclic carbonates from epoxides, even more so under organocatalytic conditions.

First, we decided to test our hypothesis with a range of $N$ containing bases using glycidol $\mathbf{A}$ as a benchmark substrate (Scheme $2 \mathrm{a}$ ). Under relatively mild conditions ( $45^{\circ} \mathrm{C}, 10$ bar) and importantly in the absence of an external nucleophile, the cyclic carbonate 1 could be easily prepared in up to $95 \%$ yield (85\% isolated) using DBU as catalyst. Several other $N$-bases were also productive in the synthesis of 1 including DMAP $(90 \%)$, TMG $(95 \%)$, MTBD $(90 \%)$ and TBD $(91 \%)$, see Scheme $2 \mathrm{~b}$. In order to be able to select a catalyst suitable for more challenging substrates (Scheme 2c), (R,R)-phenyl glycidol B was probed under suitable reaction conditions (for details: see Tables S1 and S2). Interestingly, for this internal epoxide, TBD and DBU showed the best catalytic features towards the formation of carbonates $2 a$ and $\mathbf{2 b}$, and DBU was finally selected as the preferred catalyst to investigate the conversion of trisubstituted epoxide $\mathbf{C}$ (Scheme 2d). ${ }^{[14]}$

Interestingly, when similar conditions were applied as for the mono- and di-substituted epoxide conversions ( $45^{\circ} \mathrm{C}, 10$ bar, 10 mol\% DBU), quantitative conversion of $\mathbf{C}$ into carbonates $\mathbf{3 a}$ and $\mathbf{3 b}$ was achieved $(\mathbf{3 a}: \mathbf{3 b}=\mathbf{7} \mathbf{3})$. Since $\mathbf{3} \mathbf{a}$ cannot be obtained through classical nucleophilic ring opening of the epoxide, its formation is therefore ascribed to an equilibration between $3 \mathbf{a}$ and $3 \mathbf{b}$ under the experimental conditions with a key role for DBU. This hypothesis could be confirmed as the isolated mixture of cyclic carbonates was selectively and quantitatively converted into the acetyl-protected, tri-substituted carbonate 4 (84\% isolated yield) in the presence of DBU/Aclm. ${ }^{[15]}$ Remarkably, the formation of 4 from $\mathbf{C}$ through a one-pot domino sequence was also successfully probed and provided the carbonate in $86 \%$ yield. These results imply that the acetylation step is faster for the primary alcohol with a dynamic kinetic resolution between $\mathbf{3 a}$ and $\mathbf{3} \mathbf{b}$ under basic conditions to provide elusive $\mathrm{CO}_{2}$ derived heterocycles. Furthermore, benzylated $\mathbf{C}$ was not converted by DBU in the presence of $\mathrm{CO}_{2}$, pointing at a crucial role for the alcohol unit in this conversion (see SI page S93 for details).

The successful synthesis of carbonate 4 inspired us to examine the generality of this domino process using primarily triand tetra-substituted epoxides (Figure 1). Thus, we probed more functional epoxide precursors towards the preparation of 5-8 and found that in all these cases the trisubstituted OAc-protected carbonates could be selectively formed and in high isolated yields (75-90\%). Importantly, the presence of additional double bond or epoxide groups did not interfere with the chemo-selectivity of these conversions, and only the conversion of the epoxy alcohol fragments was observed. For $\mathbf{5}$ (as observed in the synthesis of 4) a one-pot procedure was feasible and provided a higher yield of the carbonate. For all subsequent syntheses (cf., 6-13) we therefore used the one-pot three step sequence. Delightfully, the tetra-substituted carbonates 9-13 could also be prepared conveniently in appreciable yields (40-78\%) and represent the first examples of [3+2] cycloadditions between tetra-substituted epoxides and $\mathrm{CO}_{2}{ }^{[16]}$ Whereas the spiro-carbonates 9-11 were obtained under relatively mild conditions, products 12 and 13 
required harsher reaction settings. The molecular structure of $\mathbf{1 1 b}$ was also confirmed by X-ray analysis. ${ }^{[17]}$

In order to further support the mechanistic proposal that a Payne-like rearrangement takes place between carbonate products, we carried out a number of control experiments (Scheme 3). First the conversion of trisubstituted epoxide $\mathbf{C}$ was probed in the absence of $\mathrm{CO}_{2}$ to see whether classical Payne rearrangement occurs prior to carbonate formation, but no conversion of $\mathbf{C}$ into the mono-substituted epoxy alcohol D (Scheme 3a) was observed. This implies that the presence of (electrophilic) $\mathrm{CO}_{2}$ is required for the domino conversion leading to the trisubstituted carbonate product. Different pre-isolated mixtures of carbonates $\mathbf{3 a}$ and $\mathbf{3} \mathbf{b}$ (40:60 and 92:8) were then subjected to the general catalytic conditions (Scheme $3 \mathrm{~b}$ ), and both equilibrated to a 70:30 ratio. This observation supports the view that the formation of the mixture of carbonates is basemediated and follows initial formation of $\mathbf{3 b}$ from epoxy alcohol $\mathbf{C}$.

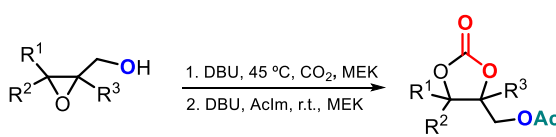

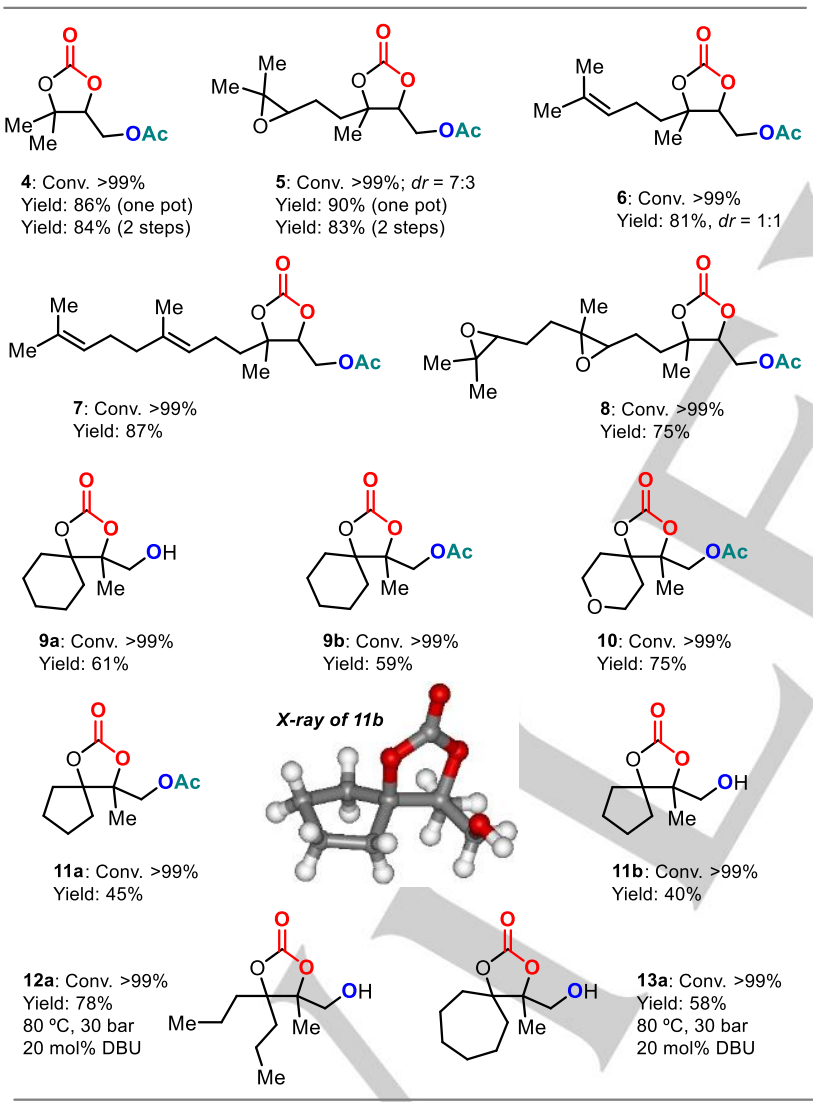

Figure 1. Scope in cyclic carbonates using a domino [3+2] cycloaddition/rearrangement sequence in the presence of DBU and Aclm. Reaction conditions: [a] epoxide $(1.0 \mathrm{mmol}), \mathrm{DBU}(10 \mathrm{~mol} \%), \mathrm{MEK}(5.0 \mathrm{~mL}), 45$ ${ }^{\circ} \mathrm{C}, p\left(\mathrm{CO}_{2}\right)^{\circ}=10$ bar, $18 \mathrm{~h}$; then DBU (1 equiv.), AcIM (1.5 equiv.), r.t., $1.5 \mathrm{~h}$.

Similar types of protected trisubstituted carbonates 14-17 (Scheme 3c) were also conveniently and selectively derived from mono-substituted epoxides having a tertiary alcohol unit, and showed the intermediate presence of carbonate mixtures prior to protection. The selective formation of $\mathbf{1 6}$, was compromised by the presence of an electron-withdrawing phenyl group that enables a faster protection than isomerization rate of the intermediate mixture of carbonates. Consequently, a lower ratio (83:17) between the protected tri- and mono-substituted carbonate was formed. ${ }^{[18]}$ The X-ray molecular structure determined for $\mathbf{1 6}$ unequivocally revealed the trisubstituted nature of the cyclic carbonate product. ${ }^{[17]}$

(a)

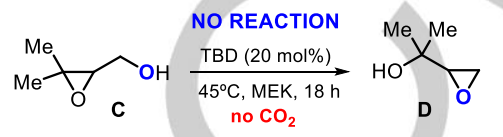

(b)

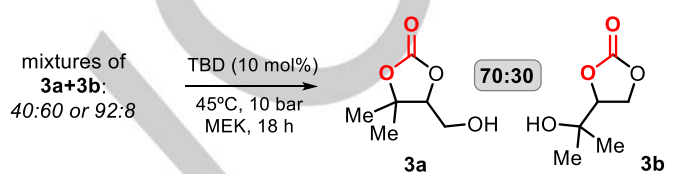

(c)
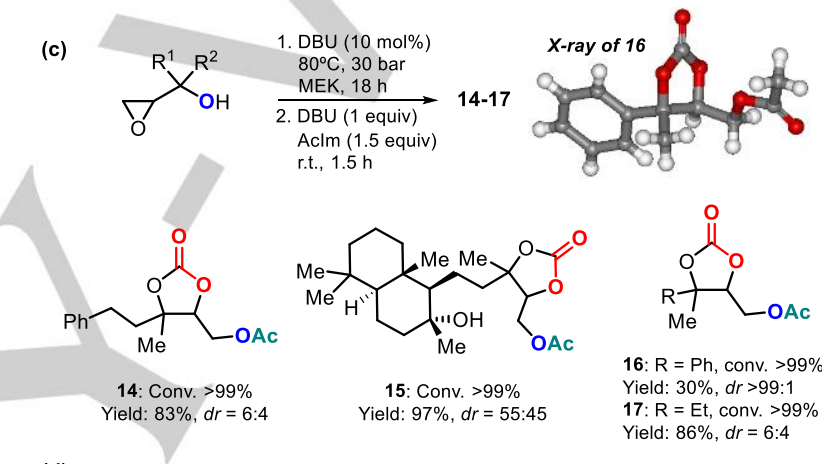

(d)

$$
\begin{array}{cl}
\text { 15: Conv. }>99 \% & \text { Yield: } 30 \%, d r>99: 1 \\
\text { Yield: } 97 \%, d r=55: 45 & 17: \mathrm{R}=\mathrm{Et}, \text { conv. }>99 \% \\
& \text { Yield: } 86 \%, d r=6: 4
\end{array}
$$

16: $\mathrm{R}=\mathrm{Ph}$, conv. $>99 \%$

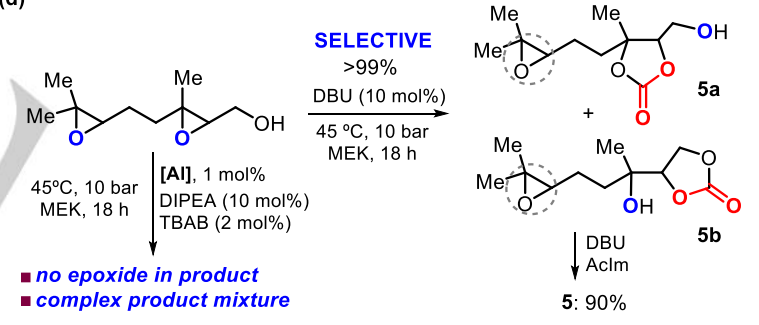

Scheme 3. Mechanistic control reactions to support the unique, organocatalytic Payne-type rearrangement at the carbonate level.

To show that the organocatalytic approach towards the preparation of these highly substituted cyclic carbonates is distinct from metal-mediated approaches, a bis-epoxide (Scheme $3 d)$ was subjected to the same conditions in the presence of an Al-based aminotriphenolate complex ${ }^{[13]}$ and the reaction mixture compared with the one obtained by using DBU as catalyst. Whereas in the latter case selective conversion of the epoxy alcohol is achieved, the use of the Al-complex leads to a complex mixture of products while converting both epoxy groups (see Supporting Information). The organocatalytic approach therefore allows for a regio-selective epoxide transformation, and offers potential to address subsequent conversion of the remaining oxirane unit. 
In conclusion, a new domino process has been developed towards the elusive coupling of tri- and tetrasubstituted epoxides and $\mathrm{CO}_{2}$ by an organocatalytic strategy. This novel reactivity allows for the synthesis of otherwise elusive cyclic carbonates under mild reaction conditions, is operationally friendly and allows for regio-selective formation of mono-carbonates using bis- or trisepoxy-based substrates. This substrate-controlled conversion of carbon dioxide offers access to new, functional heterocyclic scaffolds with amplified potential in synthetic chemistry.

\section{Acknowledgements}

We thank the CERCA Program/Generalitat de Catalunya, ICREA, the Spanish MINECO (CTQ2017-88920-P and SEV-2013-0319), and AGAUR (2017-SGR-232). S. S. thanks Covestro for support. Dr. Marta Giménez and Cristina Rivero are thanked for help with the high-pressure reactions and Dr. Noemí Cabello for the MS measurements.

Keywords: carbon dioxide $\cdot$ domino process $\bullet$ epoxy alcohols • organocatalysis $\cdot$ Payne rearrangement

[1] For general reviews: a) C. Martín, G. Fiorani, A. W. Kleij, ACS Catal 2015, 5, 1353-1370; b) J. W. Comerford, I. D. V. Ingram, M. North, X. Wu Green Chem. 2015, 17, 1966-1987; c) G. Fiorani, W. Guo, A. W. Kleij, Green Chem. 2015, 17, 1375-1389; d) M. Alves, B. Grignard, R. Mereau, C. Jerome, T. Tassaing, C. Detrembleur, Catal. Sci. Technol. 2017, 7, 2651-2684; e) M. Cokoja, M. E. Wilhelm, M. H. Anthofer, W. A. Herrmann F. E. Kühn, ChemSusChem 2015, 8, 2436-2454; f) R. Rajjak Shaikh, S. Pornpraprom, V. D'Elia, ACS Catal. 2018, 8, 419-450.

[2] For reviews see: a) T. Sakakura, J.-C. Choi, H. Yasuda, Chem. Rev. 2007, 107, 2365-2387; b) B. Schäffner, F. Schäffner, S. P. Verevkin, A. Börner, Chem. Rev. 2010, 110, 4554-4581. For polymers derived from cyclic carbonates: c) D. J. Darensbourg, A. I. Moncada, W. Choi, J. H. Reibenspies, J. Am. Chem. Soc. 2008, 130, 6523-6533; d) A. K. Diallo, E. Kirillov, M. Slawinski, J.-M. Brusson, S. M. Guillaume, J.-F. Carpentier, Polym. Chem. 2015, 6, 1961-1971; e) H. Matsukizono, T. Endo, J. Polym. Sci., A: Polym. Chem. 2016, 54, 487-497.

[3] a) N. Kielland, C. J. Whiteoak, A. W. Kleij, Adv. Synth. Catal. 2013, 355, 2115-2138; b) J. Vaitla, Y. Guttormsen, J. K. Mannisto, A. Nova, T. Repo, A. Bayer, K. H. Hopmann, ACS Catal. 2017, 7, 7231-7244; c) Y. Li, X. Cui, K. Dong, K. Junge, M. Beller, ACS Catal. 2017, 7, 1077-1086; d) M. Börjesson, T. Moragas, D. Gallego, R. Martin, ACS Catal. 2016, 6, 67396749; e) Q. Liu, L. Wu, R. Jackstell, M. Beller, Nat. Commun. 2015, 6, 5933.

[4] a) W. Guo, A. Cai, J. Xie, A. W. Kleij, Angew. Chem. Int. Ed. 2017, 56, 11797-11801; b) A. Cai, W. Guo, L. Martínez-Rodríguez, A. W. Kleij, J. Am. Chem. Soc. 2016, 138, 14194-14197; c) W. Guo, L. MartínezRodríguez, R. Kuniyil, E. Martin, E. C. Escudero-Adán, F. Maseras, A. W. Kleij, J. Am. Chem. Soc. 2016, 138, 11970-11978; d) W. Guo, L. Martínez-Rodríguez, E. Martín, E. C. Escudero-Adán, A. W. Kleij, Angew. Chem. Int. Ed. 2016, 55, 11037-11040.

[5] a) H. Wang, M. M. Lorion, L. Ackermann, ACS Catal. 2017, 7, 34303433; b) H. Wang, M. M. Lorion, L. Ackermann, Angew. Chem. Int. Ed. 2017, 56, 6339-6342; c) Q. Lu, F. J. R. Klauck, F. Glorius, Chem. Sci. 2017, 8, 3379 .
[6] a) L.-C. Yang, Z.-Q. Rong, Y.-N. Wang, Z. Y. Tan, M. Wang, Y. Zhao, Angew. Chem. Int. Ed. 2017, 56, 2927-2931; b) Z.-Q. Rong, L.-C. Yang, S. Liu, Z. Yu, Y.-N. Wang, Z. Y. Tan, R.-Z. Huang, Y. Lan, Y. Zhao, J. Am. Chem. Soc. 2017, 139, 15304-15307.

[7] a) Q. Lu, F. J. R. Klauck, F. Glorius, Chem. Sci. 2017, 8, 3379-3383; b) A. Khan, L. Yang, J. Xu, L. Y. Jin, Y. J. Zhang, Angew. Chem. Int. Ed 2014, 53, 11257-11260; c) A. Khan, R. Zheng, Y. Kan, J. Ye, J. Xing, Y. J. Zhang, Angew. Chem. Int. Ed. 2014, 53, 6439-6442; d) V. Laserna G. Fiorani, C. J. Whiteoak, E. Martin, E. Escudero-Adán, A. W. Kleij, Angew. Chem. Int. Ed. 2014, 53, 10416-10419; e) W. Guo, J. GonzálezFabra, N. A. G. Bandeira, C. Bo, A. W. Kleij, Angew. Chem. Int. Ed. 2015, 54, 11686-11690; f) Y. Liu, W.-M. Ren, K.-K. He, W.-Z. Zhang, W.-B. Li, M. Wang, X.-B. Lu, J. Org. Chem. 2016, 81, 8959-8966.

[8] For general reviews concerning their synthesis using different Lewis acids: a) A. Decortes, A. M. Castilla, A. W. Kleij, Angew. Chem. Int. Ed. 2010, 49, 9822-9837; b) P. P. Pescarmona, M. Taherimehr, Catal. Sci. Technol. 2012, 2, 2169-2187; c) M. North, R. Pasquale, C. Young, Green Chem. 2010, 12, 1514-1539.

[9] For recent contributions based on metal approaches towards trisubstituted cyclic carbonates though mostly with important limitations in scope and yields: a) G. Fiorani, M. Stuck, C. M. Martín, M. MartínezBelmonte, E. Martin, E. C. Escudero-Adán, A. W. Kleij, ChemSusChem 2016, 9, 1304-1311; b) J. Martínez, J. Fernández-Baeza, L. F. SánchezBarba, J. A. Castro-Osma, A. Lara-Sánchez A. Otero, ChemSusChem 2017, 10, 2886-2890; c) C. Maeda, J. Shimonishi, R. Miyazaki, J.-Y. Hasegawa, T. Ema, Chem. Eur. J. 2016, 22, 6556-6563; d) V. Laserna, E. Martin, E. C. Escudero-Adán, A. W. Kleij, ACS Catal. 2017, 7, 54785482; e) L. Longwitz, J. Steinbauer, A. Spannenberg, T. Werner, ACS Catal. 2018, 8, 665-672.

[10] For a compelling review on naturally occurring organic carbonates: $\mathrm{H}$. Zhang, H.-B. Liu, J.-M. Yue, Chem. Rev. 2014, 114, 883-898.

[11] a) C. J. Whiteoak, E. Martin, E. C. Escudero-Adán, A. W. Kleij, Adv. Synth. Catal. 2013, 355, 2233-2239; b) C. J. Whiteoak, N. Kielland, V. Laserna, E. C. Escudero-Adán, E. Martin, A. W. Kleij, J. Am. Chem. Soc. 2013, 135, 1228-1231.

[12] G. B. Payne, J. Org. Chem. 1962, 27, 3819-3822.

[13] J. Rintjema, R. Epping, G. Fiorani, E. Martín, E. C. Escudero-Adán, A. W. Kleij, Angew. Chem. Int. Ed. 2016, 55, 3972-3976.

[14] Note that the known, nucleophilic bromide-based catalyst TBAB showed a combined yield of only $7 \%$ for $\mathbf{2} \mathbf{a} / \mathbf{2} \mathbf{b}(\mathbf{2} \mathbf{a}: \mathbf{2} \mathbf{b}=55: 45)$, see the Supporting Information for details. This demonstrates that the in situ formation of a nucleophilic species derived from the epoxy alcohol substrate is far more effective than the use of an external nucleophile.

[15] Primary alcohols can be easily protected using Aclm, see: a) $\mathrm{H}$. Hagiwara, K. Morohashi, T. Suzuki, M. Ando, I. Yamamoto, M. Kato, Synth. Commun. 1998, 28, 2001-2006; b) R. C. Pratt, B. G. G. Lohmeijer, D. A. Long, R. M. Waymouth, J. L. Hedrick, J. Am. Chem. Soc. 2006, 128, 4556-4557.

[16] For the one-pot reactions towards 9-13 typically we found 8:2 ratios between the desired tetra-substituted carbonate and a disubstituted one contrary to the syntheses of trisubstituted carbonate products 4-8. This observation indicates that the acetyl-protection (third step in the one-pot synthesis) is more competitive because of a slower base-induced equilibration of both carbonates. For this reason most of the unprotected tetrasubstituted carbonates were directly isolated.

[17] For details, see CCDC 1832243 and 1832244

[18] Pure trisubstituted carbonate 21 was isolated (30\%) as a single diastereoisomer $(d r>99: 1)$ by chromatographic separation; note however, that initially quantitative formation of a mixture of both the triand monosubstituted carbonate occurred (ratio tri/mono $=83: 17, d r=$ 57:43 for the trisubstituted product) 


\section{Entry for the Table of Contents:}

\section{COMMUNICATION}

No Payne, no gain: A domino [3+2] cycloaddition/Payne type rearrangement allows for the synthesis of elusive heterocycles from carbon dioxide and epoxy alcohols. This attractive, metal-free and operationally simple approach affords a wide range of substitutionally dense and functional cyclic carbonates. The mechanistic manifold towards these scaffolds shows resemblance with the Payne rearrangement of epoxy alcohols as shown by various control experiments.
- Metal- and additive-free

- Domino [3+2] coupling/rearrangement

- Elusive heterocycles

- Mild reaction conditions<smiles>[R4]CC1([R3])OC(=O)OC1([R])[R]</smiles>

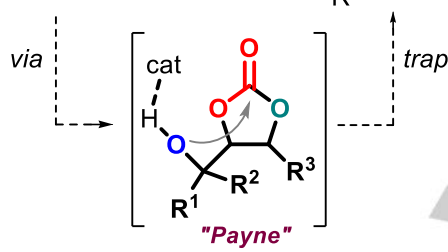

Sergio Sopeña, Mariachiarra Cozzolino, Cristina Maquilón, Eduardo C. EscuderoAdán, Marta Martínez Belmonte and Arjan W. Kleij ${ }^{*}$

\section{Page No. - Page No.}

\section{Organocatalyzed Domino [3+2]}

Cycloaddition/Payne-Type Rearrangement using Carbon Dioxide and Epoxy Alcohols 